\title{
Patterns of Adherence to Oral Atypical Antipsychotics Among Patients Diagnosed with Schizophrenia
}

\author{
Joanna P. MacEwan, PhD; Felicia M. Forma, BSc; Jason Shafrin, PhD; Ainslie Hatch, PhD;
} Darius N. Lakdawalla, PhD; and Jean-Pierre Lindenmayer, MD

\begin{abstract}
BACKGROUND: Poor medication adherence contributes to negative treatment response, symptom relapse, and hospitalizations in schizophrenia. Many health plans use claims-based measures like medication possession ratios or proportion of days covered (PDC) to measure patient adherence to antipsychotics. Classifying patients solely on the basis of a single average PDC measure, however, may mask clinically meaningful variations over time in how patients arrive at an average PDC level.
\end{abstract}

OBJECTIVE: To model patterns of medication adherence evolving over time for patients with schizophrenia who initiated treatment with an oral atypical antipsychotic and, based on these patterns, to identify groups of patients with different adherence behaviors.

METHODS: We analyzed health insurance claims for patients aged $\geq 18$ years with schizophrenia and newly prescribed oral atypical antipsychotics in 2007-2013 from 3 U.S. insurance claims databases: Truven MarketScan (Medicaid and commercial) and Humana (Medicare). Group-based trajectory modeling (GBTM) was used to stratify patients into groups with distinct trends in adherence and to estimate trends for each group. The response variable was the probability of adherence (defined as $P D C \geq 80 \%$ ) in each 30-day period after the patient initiated antipsychotic therapy. GBTM proceeds from the premise that there are multiple distinct adherence groups. Patient demographics, health status characteristics, and health care resource use metrics were used to identify differences in patient populations across adherence trajectory groups.

RESULTS: Among the 29,607 patients who met the inclusion criteria, 6 distinct adherence trajectory groups emerged from the data: adherent $(33 \%)$; gradual discontinuation after 3 months (15\%), 6 months (7\%), and 9 months (5\%); stop-start after 6 months (15\%); and immediate discontinuation (25\%). Compared to patients 18-24 years of age in the adherent group, patients displaying a stop-start pattern after 6 months had greater odds of having a history of drug abuse $(\mathrm{OR}=1.46 ; 95 \% \mathrm{Cl}=1.26-1.66 ; P<0.001)$, alcohol abuse $(0 \mathrm{R}=1.34 ; 95 \% \mathrm{Cl}=1.14-1.53 ; P<0.001)$, and a codiagnosis of major depressive disorder $(0 \mathrm{R}=1.24 ; 95 \% \mathrm{Cl}=1.05-1.44 ; P<0.001)$ and were less likely to be aged $35-54$ years $(0 \mathrm{R}=0.66 ; 95 \% \mathrm{Cl}=0.46-0.85 ; P<0.001)$.

CONCLUSIONS: Longitudinal medication adherence patterns can be expressed as distinct trajectories associated with specific patient characteristics and health care utilization patterns. We found 6 distinct patterns of adherence to antipsychotics over 12 months. Patients in different groups may warrant different types of clinical interventions to prevent hospitalizations, longer hospital stays, and increased clinical complexity. For example, clinicians may consider regular home visits, assertive community treatment, and other related interventions for patients at high risk of immediate discontinuation. Health plans should consider supplementing claims-based adherence measures with new technologies that are able to track patient adherence patterns over time.

J Manag Care Spec Pharm. 2016;22(11):1349-61

Copyright $\odot 2016$, Academy of Managed Care Pharmacy. All rights reserved.

\section{What is already known about this subject}

Medication nonadherence of patients with schizophrenia can lead to inadequate symptom control, relapse, and hospitalization and increases health care resource utilization and costs.

Patients' medication adherence patterns may vary over a given period of time and may require substantially different clinical intervention timing

Timing of adherence problems has clinical and economic ramifications, and timely identification of nonadherence enables targeted intervention and prevention of further deterioration in adherence and health.

\section{What this study adds}

Current methods used by health plans to measure medication adherence cannot distinguish between distinct dynamic patterns of adherence.

Using group-based trajectory modeling, this study models how adherence evolves dynamically over time for schizophrenia patients and assesses how patient characteristics influence the way adherence evolves.

Identifying a patient's adherence trajectory may facilitate customization of interventions to improve medication adherence.

T he goals of treatment with antipsychotic medication in schizophrenia are to reduce or eliminate symptoms, maximize patient functioning, and maintain recovery over the long term. ${ }^{1}$ However, poor medication adherence (as traditionally measured) contributes to negative treatment response, ${ }^{2}$ symptom relapse, ${ }^{3,4}$ and hospitalization. ${ }^{5}$ Relapse rates may be up to 5 times higher in patients who discontinue their antipsychotic medication than in those who continue treatment. ${ }^{1,6}$ Even brief $(<2$-week) gaps in oral antipsychotic medication coverage have been shown to increase the risk of relapse ${ }^{7}$ and hospitalization. ${ }^{8,9}$ These episodes of relapse contribute to the high cost of care for schizophrenia patients, estimated to equal $\$ 155.7$ billion in 2013. ${ }^{10}$

Many health plans use claims-based adherence measures to monitor patient adherence to antipsychotic medications. For instance, the National Committee for Quality Assurance has a Healthcare Effectiveness Data and Information Set quality measure based on the percentage of patients with 
schizophrenia who have a proportion of days covered (PDC) of $\geq 80 \%{ }^{11}$ Grouping patients together based on a single PDC threshold, however, likely masks pivotal points during treatment when patients' adherence patterns change within the overall time frame. ${ }^{12}$ Medication adherence is a dynamic phenomenon, ${ }^{13}$ and adherence varies over the course of treatment and in daily dosing of medication, rendering inadequate a simple classification of each patient as "adherent" or "nonadherent." In practice, patients with the same PDC-based adherence measure can exhibit very different patterns of adherence. For instance, patient A may consistently fill (and presumably take) their medication the first half of the year, but not refill in the second half, whereas patient B might fluctuate between filling their prescription one month but not the next. Both patients would exhibit the same aggregate PDC measure (50\%) and be considered nonadherent, but each may call for substantially different clinical interventions at different times. ${ }^{14}$

More information about detailed and dynamic adherence patterns in patients with schizophrenia could advance the ability of health care professionals to accurately identify subgroups of patients and customize interventions to improve medication adherence..$^{15,16}$ Deeper understanding of the key characteristics predictive of various adherence patterns could further aid in individually tailoring adherence programs to the right patients at the right time.

To help define a dynamic taxonomy of medication nonadherence, this study applied group-based trajectory modeling (GBTM) to model adherence to antipsychotic medication over time for patients diagnosed with schizophrenia who initiated treatment with an oral atypical antipsychotic. GBTM has been used to identify distinct patient groups with a particular adherence trajectory behavior and to identify individual characteristics associated with membership in each group. ${ }^{12,17}$ This group-based approach does not restrict researchers and providers to classifying patients into crude categories of adherent or nonadherent individuals. Rather, it permits the measurement of more nuanced and dynamic patterns of adherence, which likely have different clinical and economic ramifications. This method has been previously used to study patterns of adherence to statins and to biologic treatments for psoriasis, ${ }^{12,14}$ but to our knowledge this is the first application of GBTM for patients with serious mental illness (SMI). Since adherence in SMI is complex and dynamic, we hypothesized that several unique adherence patterns would emerge in the SMI population and confirm the dynamic nature of adherence.

\section{Methods}

\section{Study Design and Data Sources}

This retrospective claims analysis used data from Truven Health Analytics' MarketScan Commercial Claims and Encounters database and the MarketScan Medicaid Multi-State Database (September 1, 2007-March 31, 2013) and Humana's
Medicare database (January 1, 2007-December 31, 2012). The MarketScan commercial database includes medical and pharmacy claims for nearly 8 million individuals and their dependents who are covered through employer-sponsored private health insurance plans. The MarketScan Medicaid database includes medical and pharmacy claims for 1.2 million Medicaid beneficiaries from 11 geographically dispersed states. The Medicare database is drawn from a single payer, Humana, which is the second-largest provider of Medicare Advantage plans in the United States. Humana's Medicare database includes medical and pharmacy claims and patient demographic and insurance eligibility status information for 13.3 million individuals enrolled in a Humana Medicare Advantage and/or a Medicare Part D plan. The Humana Medicare data contain Medicare Advantage patients. It is worth noting that Truven MarketScan also produces a database with Medicare beneficiaries covered by Medicare Supplemental insurance. Neither choice contains a truly representative sample of Medicare patients overall. Nonetheless, we elected to use the Humana database, because Medicare Advantage has a fastergrowing population than the fee-for-service population. ${ }^{18}$ The latter characteristics might be associated with higher general health status than the general Medicare population.

Medical claims from facilities and providers included International Classification of Diseases, Ninth Revision, Clinical Modification (ICD-9-CM) diagnosis codes, procedure codes, site of service codes, provider specialty codes, and health plan and patient costs. Data from outpatient pharmacy claims included National Drug Code (NDC) numbers for dispensed medications, quantity dispensed, drug strength, days' supply, and health plan and patient costs.

All study data were deidentified and accessed in compliance with the Health Insurance Portability and Accountability Act (HIPAA) of 1996. No identifiable protected health information was extracted or assessed during the course of the study. Pursuant to HIPAA, the use of deidentified data does not require institutional review board approval or waiver of authorization. ${ }^{19}$

\section{Study Population and Cohort Assignment}

We identified patients $\geq 18$ years of age with a pharmacy claim for an oral atypical antipsychotic in the commercial, Medicaid, and Medicare databases. Oral atypical antipsychotic NDC numbers were identified using molecule names in the Truven RED BOOK database. Patients were required to have $\geq 1$ inpatient or $\geq 2$ outpatient claims with an ICD-9-CM diagnosis code for schizophrenia (295.x) (including schizoaffective disorder) on or before the date of therapy initiation. We defined the date of therapy initiation by identifying the first observed prescription fill for an oral atypical antipsychotic. Patients were required to be continuously enrolled in their health plans for $\geq 18$ months: 6 months prior to the date they initiated therapy 
(pretherapy initiation period) and 12 months following the date of therapy initiation (posttherapy follow-up period).

We required that a patient have a schizophrenia diagnosis and no atypical antipsychotic prescriptions during this 6-month pretherapy initiation period. Subsequent adherence to any oral atypical antipsychotic was used in the analysis. We excluded patients using long-acting injectables but not short-acting injectables from the study. However, short-acting injectables were not included in the adherence measurement because adherence to injectables uniquely depends on physician access, not just patient behavior. Short-acting injectables are mostly used in acute care or emergencies and not as a long-term intervention. ${ }^{20}$ Adherence was measured for atypical oral antipsychotics (aripiprazole, asenapine, iloperidone, lurasidone, olanzapine, paliperidone, quetiapine, risperidone, ziprasidone). Patients using clozapine were not included in the sample because clozapine requires continued monitoring and physician supervision, ${ }^{21}$ which are likely to exert an independent influence on prescription refill and adherence rates. ${ }^{20}$ Patients with claims for mail-ordered antipsychotics were also excluded to control for potential confounding from automatic drug fills that might overstate actual medication adherence, ${ }^{5,22}$

\section{Variables}

The response variable was the probability of adherence (defined as PDC $\geq 80 \%$ ) to one or more atypical antipsychotics in each 30-day period after the patient initiated atypical antipsychotic therapy. PDC was calculated as the number of days supply for atypical antipsychotics in the 12 months following therapy initiation, divided by 365 days, and subject to a maximum value of $100 \%$. We used a 12 -month follow-up period as it corresponds with the typical 12-month PDC measurement period and facilitates comparison of adherence as described by adherence trajectories versus the typical PDC measure. Monthly PDC (the number of days supply for an oral antipsychotic in a given month divided by 30 days) was also calculated and capped at $100 \%$. Patients with PDC $\geq 80 \%$ in a given month were considered adherent in the sense that their monthly adherence indicator was set to $1 .{ }^{23,24}$ If a patient was dispensed an atypical antipsychotic before the end of the days supply for their previous dispensing, the extra days supply was applied to the following month's PDC. To account for medication dispensed during inpatient stays, monthly PDC was adjusted in accordance with the PDC measure calculated by the Centers for Medicare \& Medicaid Services' Medicare Parts C\&D Star Rating system. ${ }^{25}$ If a patient was admitted to the hospital, it was assumed that they were adherent during the stay and that any days supply of atypical antipsychotic overlapping the inpatient stay was applied to the postadmission period's PDC.

Patient demographics, health status characteristics, and health care resource use metrics were used to identify differences in patient populations across adherence trajectory groups. Baseline patient demographic characteristics included categorical age at therapy initiation, sex, and health insurance plan. Clinical characteristics included codiagnoses and other conditions (bipolar disorder [BPD], major depressive disorder [MDD], alcoholism, and drug abuse) during the 6-month pretherapy initiation period and were based on ICD-9-CM diagnosis codes on $\geq 1$ inpatient or $\geq 2$ outpatient medical claims. Although an ICD-9-CM diagnosis of schizophrenia should exclude concurrent diagnosis of BPD or MDD, these codes may still coexist in medical claims records for an individual patient. ICD-9-CM diagnosis codes from medical claims were also used to calculate the Charlson Comorbidity Index (CCI). ${ }^{26}$ We included measures of care by a psychiatrist (i.e., the share of claims for outpatient visits during the 6-month preinitiation period where the health care professional was a psychiatrist as determined by provider specialty codes), repeated provider interactions (i.e., having $\geq 2$ claims for outpatient visits with the same health care professional in the 6-month preinitiation period), and mental health-related (MHR; defined as having a diagnosis code for schizophrenia, MDD, and/or BPD in any position) emergency department (ED) visits and psychiatric inpatient admissions (identified using the "psychiatric or substance abuse" admission-type information) in the 6 months before initiating antipsychotic therapy. The primary outcome of interest for health care resource use was patient use of acutecare services for MHR causes, which was measured based on psychiatric inpatient admissions and MHR ED visits for any cause in the 12 months after initiating antipsychotic therapy.

\section{Statistical Analysis}

The GTBM approach is a 5-step process that includes (1) measuring medication adherence each month; (2) selecting the number of possible trajectory groups; (3) using a maximum likelihood approach that uses data on time-invariant individual characteristics to fit the model that best predicts adherence behavior, given that each patient could belong to any one of the several different adherence groups ${ }^{12}$; (4) predicting the probability of belonging to each group; and (5) assigning patients to the group where they have the highest predicted probability of membership. Within each adherence group, the probability of adherence in a given month was modeled as a smooth function of time using a third-degree polynomial function. The adherence trajectory curve for each adherence group and the probability that a given individual belonged to a particular group were estimated using the data, not assumed a priori. The Bayesian Information Criterion (BIC) statistic was used to select the model with the optimal number of trajectory groups to describe the data. ${ }^{17}$ 


\begin{tabular}{|c|c|c|c|c|}
\hline & $\begin{array}{l}\text { Commercial } \\
\mathbf{n}(\%)\end{array}$ & $\begin{array}{l}\text { Medicaid } \\
\text { n (\%) }\end{array}$ & $\begin{array}{l}\text { Medicare } \\
\text { n (\%) }\end{array}$ & $\begin{array}{l}\text { Total } \\
\text { n }(\%) \\
\end{array}$ \\
\hline $\begin{array}{l}\text { Health plan enrollees between September 1, 2007, and March 31, } \\
2013 \text { (January 1, 2007, and December 31, 2012, for Medicare) }\end{array}$ & $7,651,159(100.0)$ & $1,246,146(100.0)$ & $13,314,377(100.0)$ & $22,211,682(100.0)$ \\
\hline Aged $\geq 18$ years & $7,186,364$ & $1,048,683$ & $12,317,405$ & $20,552,452$ \\
\hline Oral atypical antipsychotic prescription claim & $653,483 \quad(8.5)$ & 288,269 & 557,038 & $1,498,790$ \\
\hline $\begin{array}{l}\text { Patients with } \geq 1 \text { inpatient or } \geq 2 \text { outpatient claims with ICD-9-CM } \\
\text { diagnosis code for BPD (296.0x-296.1x, 296.4x-296.8x), MDD } \\
\text { (296.2x-296.3x, 311.x), or schizophrenia (295.x) during the 6-month } \\
\text { pre-index prescription period }\end{array}$ & 298,670 & $136,294 \quad(10.9)$ & 40,653 & 475,617 \\
\hline $\begin{array}{l}\text { Continuous enrollment for } \geq 18 \text { months ( } 6 \text { months pre- and } 12 \\
\text { months post-antipsychotic initiation) }\end{array}$ & $133,303 \quad(1.7)$ & $74,634 \quad(5.9)$ & 16,520 & 224,457 \\
\hline $\begin{array}{l}\text { Exclude patients who received index prescription via mail order or } \\
\text { where the oral atypical wasn't the first antipsychotic }\end{array}$ & 106,877 & 67,317 & 12,922 & 187,116 \\
\hline $\begin{array}{l}\text { Exclude patients who switched to a long-acting injectable or whose } \\
\text { index prescription was for clozapine }\end{array}$ & 106,424 & 65,277 & 12,878 & 184,579 \\
\hline Patients with a schizophrenia diagnosis & 5,521 & 22,516 & 1,570 & 29,607 \\
\hline
\end{tabular}

We assessed patient demographics as of the date of therapy initiation as predictors of membership in each trajectory group. Age was categorized into 6 groups, with $75+$ years as the reference category. Commercial insurance coverage was the reference group for the insurance type variable. Using logistic regression, we estimated the independent effect of each patient characteristic on the relative odds (odds ratios [ORs]) of belonging to each group relative to the most adherent group. We also estimated generalized negative binomial regression models of the number of acute-care events (psychiatric inpatient admissions and MHR ED visits) as a function of adherence trajectory group membership and patient characteristics. The results are reported as incidence rate ratios (IRRs).

All statistical analyses were performed using Stata-MP, version 13.0 (StataCorp, College Station, TX).

\section{Results}

\section{Study Population}

A total of 29,607 patients with a schizophrenia diagnosis met the selection criteria (Table 1). Of these, 22,516 were Medicaid-insured, 5,521 were commercially insured, and 1,570 were insured by Medicare. The overall study population included $51.3 \%$ women and had a mean age of 43 years (Appendix A, available in online article). Our estimates of the prevalence of substance (drugs and/or alcohol) abuse among patients with schizophrenia are in line with a similar study that used a MarketScan database ${ }^{27} ; 22.4 \%$ of patients in the overall sample had a codiagnosis of alcoholism and $13.0 \%$ had a history of drug abuse (Table 2).

\section{Adherence Groups Based on Trajectory Model}

Figure 1 illustrates the adherence GBTMs. Models with 3 (Figure 1A), 4 (Figure 1B), 5 (Figure 1C), and 6 (Figure 1D) adherence trajectories are depicted. Models with more than 6 groups are estimable but would have low within-group sample sizes and be less tractable. A 6-group model was found to fit the data best based on its BIC value (Appendix B, available in online article). In this model, the 6 groups can be categorized into 4 broad adherence patterns: adherent, gradual discontinuation, stop-start, and immediate discontinuation. The adherent group displayed high levels of adherence throughout the observation period and was estimated to make up 33.2\% of the sample population (Table 2). The 3 gradual discontinuation groups, where adherence fell below $25.0 \%$ within 3,6 , or 9 months after therapy initiation, together comprised $26.6 \%$ of the sample: $5.1 \%$ reached discontinuation levels at 9 months, $6.5 \%$ reached discontinuation levels at 6 months, and $15.0 \%$ reached discontinuation levels at 3 months. One group exhibited a stop-start adherence pattern that declined initially and then increased after 6 months and made up 15.3\% of the sample. The immediate discontinuation group, in which adherence fell below $25.0 \%$ after just 1 month, made up $24.9 \%$ of the sample.

Given our relatively small Medicare patient sample, ${ }^{28}$ we conducted a sensitivity analysis to examine whether the number of trajectory groups or adherence patterns were significantly different among Medicare patients. We found no qualitative differences in the number or shape of adherence patterns in Medicare patients. There were some slight differences in the distribution of Medicare patients across groups compared with the distribution of all patients. The shares of Medicare patients in the stop-start at 6 months, discontinuation after 9 months, and immediate discontinuation groups were lower at $12.1 \%$, $4.1 \%$, and $19.6 \%$, respectively, but the share in the adherent group was very similar (33.3\%). There were greater shares of Medicare patients in the discontinuation after 3 and 6 months groups at $8.4 \%$ and $22.4 \%$, respectively. 


\begin{tabular}{|c|c|c|c|c|c|c|c|}
\hline & \multicolumn{7}{|c|}{ Adherence Trajectory Group } \\
\hline & \multirow[b]{2}{*}{ Adherent } & \multirow{2}{*}{\begin{tabular}{|c|} 
Discontinuation \\
9 Months
\end{tabular}} & \multirow{2}{*}{$\begin{array}{c}\text { Discontinuation } \\
6 \text { Months } \\
\end{array}$} & \multirow{2}{*}{\begin{tabular}{|c|} 
Discontinuation \\
3 Months \\
\end{tabular}} & Stop-Start & \multirow{2}{*}{$\begin{array}{c}\text { Immediate } \\
\text { Discontinuation }\end{array}$} & \multirow[b]{2}{*}{ Overall } \\
\hline & & & & & & & \\
\hline & $(\mathrm{n}=9,838)$ & $(\mathrm{n}=1,497)$ & $(\mathrm{n}=1,937)$ & $(n=4,448)$ & $(n=4,525)$ & $(\mathbf{n}=7,361)$ & $(\mathrm{N}=29,607)$ \\
\hline Percentage of total sample & 33.2 & 5.1 & 6.5 & 15.0 & 15.3 & 24.9 & 100.0 \\
\hline \multicolumn{8}{|c|}{ Treatment history (6 months pre-index), \% (SD) } \\
\hline $\begin{array}{l}\text { ED MHR admission } \\
6 \text { months pre-index }\end{array}$ & $15.4(36.1)$ & $20.2(40.1)$ & $20.0 \quad(40.0)$ & $25.0 \quad(43.3)$ & $22.9 \quad(42.0)$ & $27.8 \quad(44.8)$ & $21.7 \quad(41.2)$ \\
\hline $\begin{array}{l}\text { Inpatient psych admission } \\
6 \text { months pre-index }\end{array}$ & $13.1 \quad(33.7)$ & $17.8(38.3)$ & $(37.3)$ & $22.8 \quad(42.0)$ & $16.7 \quad(37.3)$ & $24.6 \quad(43.1)$ & $18.4(38.8)$ \\
\hline $\begin{array}{l}\text { Share of OP visits with } \\
\text { psychiatrist }\end{array}$ & $24.7 \quad(41.8)$ & $(42.5)$ & $32.3(45.1)$ & $20.1 \quad(37.9)$ & $22.6 \quad(40.0)$ & $16.8(35.0)$ & $(39.8)$ \\
\hline $\begin{array}{l}\text { Repeated provider } \\
\text { interactions }\end{array}$ & $36.4(48.1)$ & $41.8 \quad(49.3)$ & $48.4 \quad(50.0)$ & $38.1 \quad(48.6)$ & $37.0 \quad(48.3)$ & $36.3(48.1)$ & $37.8(48.5)$ \\
\hline \multicolumn{8}{|c|}{ Codiagnoses and other conditions (6 months pre-index), \% (SD) } \\
\hline Alcoholism & $15.3(36.0)$ & $21.3(41.0)$ & $19.6(39.7)$ & $26.7 \quad(44.2)$ & $23.4(42.3)$ & $29.6 \quad(45.7)$ & $(41.7)$ \\
\hline Drug abuse & $7.8 \quad(26.9)$ & $12.9(33.6)$ & $11.3(31.6)$ & $15.5 \quad(36.2)$ & $13.5(34.2)$ & $18.5(38.9)$ & $(33.7)$ \\
\hline \multicolumn{8}{|c|}{ Adherence (12 months post-index), \% (SD) } \\
\hline PDC & $98.9 \quad(3.2)$ & $76.4 \quad(11.1)$ & $69.7(14.4)$ & $42.6(13.1)$ & $74.3 \quad(17.1)$ & $18.4(12.2)$ & $(34.2)$ \\
\hline \multicolumn{8}{|l|}{ PDC categorical } \\
\hline $0 \%-25 \%$ & $(0.0)$ & $(0.0)$ & $(0.0)$ & $1.6(12.5)$ & $(0.0)$ & $71.3 \quad(45.2)$ & $(39.1)$ \\
\hline $26 \%-50 \%$ & $(1.0)$ & $(9.7)$ & $1.6(12.5)$ & $66.7 \quad(47.1)$ & $7.8 \quad(26.8)$ & $25.5 \quad(43.6)$ & $(37.7)$ \\
\hline $51 \%-75 \%$ & $(1.0)$ & $30.7(46.1)$ & $62.0 \quad(48.6)$ & $29.3 \quad(45.5)$ & $35.3 \quad(47.8)$ & $3.0 \quad(17.1)$ & $(36.5)$ \\
\hline $76 \%-100 \%$ & $100.0 \quad(1.4)$ & $68.4 \quad(46.5)$ & $36.4 \quad(48.1)$ & $2.4 \quad(15.4)$ & $56.9 \quad(49.5)$ & $(3.9)$ & $48.2 \quad(50.0)$ \\
\hline \multicolumn{8}{|c|}{ Acute care use (12 months post-index), \% (SD) } \\
\hline ED visits, number & $1.7 \quad(4.1)$ & $(4.5)$ & $(4.3)$ & (4.8) & (5.1) & (6.8) & $(5.2)$ \\
\hline $\begin{array}{l}\text { Inpatient admissions, } \\
\text { number }\end{array}$ & $(5.6)$ & $(2.2)$ & $(2.1)$ & (1.8) & (3.4) & (1.4) & (3.7) \\
\hline
\end{tabular}

\section{Patient Characteristics Across Adherence Groups}

Patient demographics, codiagnoses and other conditions, and health varied across groups (Table 2). The share of patients with schizophrenia who also were diagnosed with MDD during the 6-month period before initiation of an atypical antipsychotic ranged from $45.6 \%$ in the adherent group to $57.1 \%$ in the discontinuation after 3 months group; the share of schizophrenia patients who were codiagnosed with BPD ranged from $40.1 \%$ in the adherent group to $47.7 \%$ in the discontinuation after 3 months group. In addition, alcoholism and drug abuse appeared to be risk factors for belonging to the immediate discontinuation group or the stop-start group, rather than the adherent group (Table 3). Using the regression-based approach, we found that relative to patients aged 18-24 years with commercial insurance in the adherent group, patients displaying a stop-start pattern after 6 months were more likely to have a history of drug abuse $(\mathrm{OR}=1.46 ; 95 \% \mathrm{CI}=1.26-1.66$; $P<0.001)$, a history of alcohol abuse (OR $=1.34 ; 95 \% \mathrm{CI}=1.14$ 1.53; $P<0.001)$, or a co-diagnosis with $\mathrm{MDD}(\mathrm{OR}=1.24 ; 95 \%$ $\mathrm{CI}=1.05-1.44 ; P<0.001)$ and they were less likely to be $35-54$ years of age $(\mathrm{OR}=0.66 ; 95 \% \mathrm{CI}=0.46-0.85 ; P<0.001$; Table 3 and Appendix B). Claims related to alcoholism and drug abuse during the pretherapy initiation period were lowest for the adherent group at $15.3 \%$ and $7.8 \%$, respectively, and highest for those in the immediate discontinuation group at $29.6 \%$ and $18.5 \%$, respectively.

\section{Health Care Resource Use}

Adherent patients had significantly fewer MHR ED visits compared with patients in most other trajectory groups in the 6 months prior to and 12 months after initiating antipsychotic therapy, but they had more frequent psychiatric admissions. For example, patients in the stop-start after 6 months group had 25.6\% more MHR ED visits than patients in the adherent group (IRR=1.256, $P<0.001$ ) in the 12 months after initiating antipsychotic therapy, but patients who discontinued after 6 months had 18.0\% fewer psychiatric admissions in the 12-month follow-up period than the adherent group (IRR $=0.820 ; P=0.003$; Figure 2). The average number of MHR ED visits in the 12-month period following therapy initiation was lowest in the adherent group (1.72) and highest in the stop-start after 6 months group (2.54) and in the immediate 


\section{A. Three Groups}

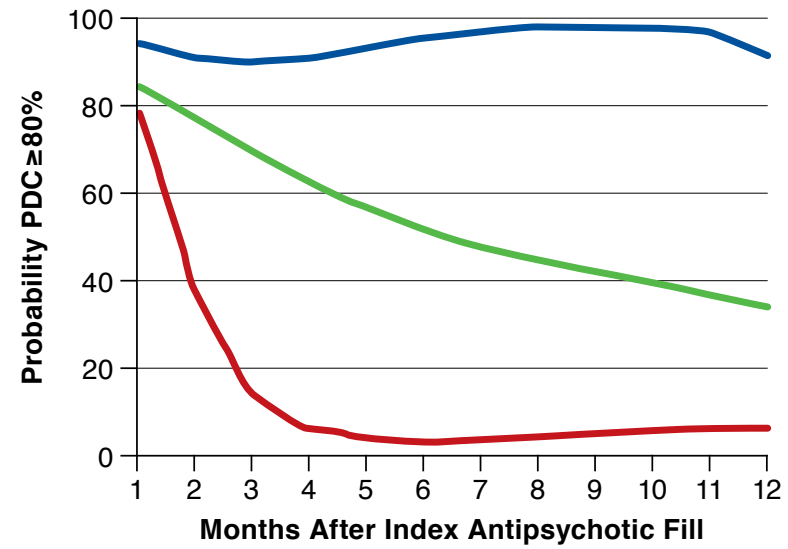

\section{Five Groups}

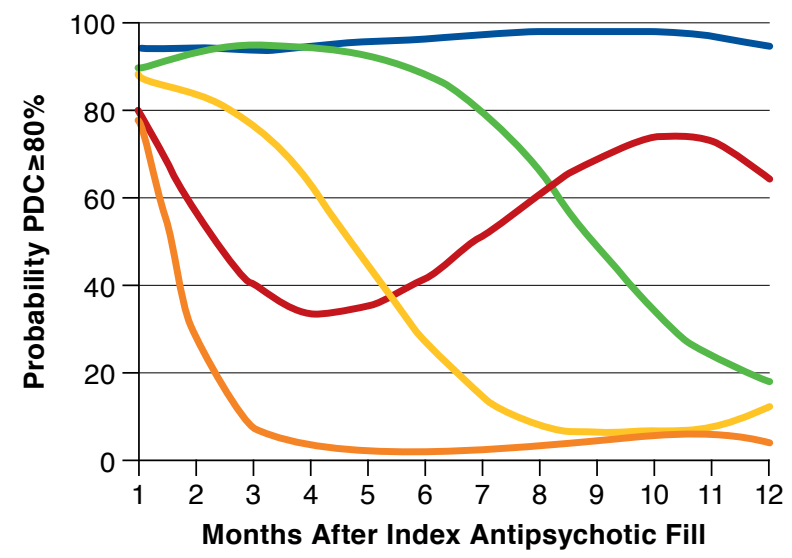

\section{B. Four Groups}

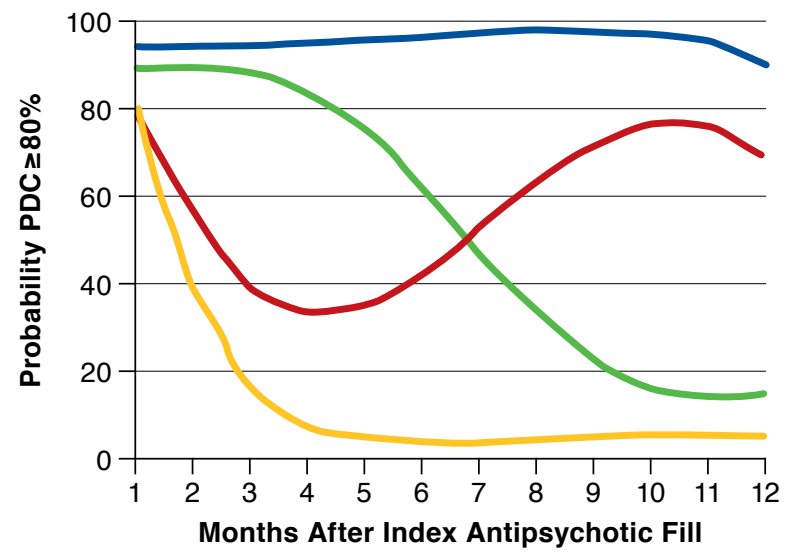

D. Six Groups ${ }^{a}$

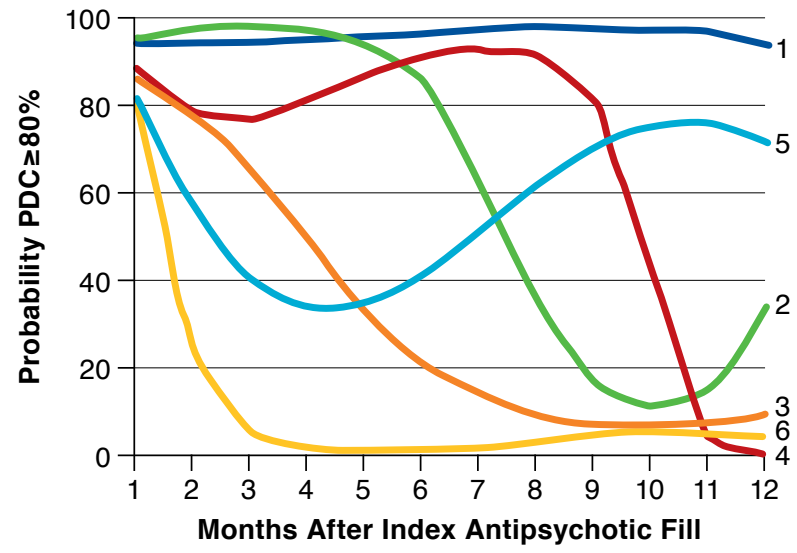

aFor the 6-group model, group 1 = adherent; group 2 = discontinuation, 6 months; group $3=$ discontinuation, 3 months; group $4=$ discontinuation, 9 months; group $5=$ stopstart, 6 months; and group $6=$ immediate discontinuation.

discontinuation group (2.85) (statistical significance not tested; Table 2). Pre-index MHR ED visits and psychiatric inpatient admissions were least frequent in the adherent group-15.4\% and $13.1 \%$, respectively-and most common in the immediate discontinuation group (27.8\% and $24.6 \%$, respectively).

\section{Discussion}

Medication adherence is a dynamic phenomenon, and nonadherence behavior could be a result of patients not initiating, maintaining, or persisting with their treatment regimen. ${ }^{13}$ To our knowledge, this study is the first to apply the GBTM method to uncover the dynamic trajectories of adherence behavior in the SMI population. Our results suggest that adherence patterns for SMI patients may be more varied than research based on simple aggregate measures of PDC would suggest.
The observation of a larger share of patients with schizophrenia in the Medicaid database relative to the commercial and Medicare databases is consistent with similar database studies $^{29}$ and is representative of the schizophrenia population in the United States given the early age of onset and associated high loss of productivity. ${ }^{30}$ There were 6 distinct adherence trajectory groups best describing the overall sample: adherent (33.2\%); discontinuation after 3 months (15.0\%), 6 months (6.5\%), and 9 months (5.1\%); stop-start after 6 months (15.3\%); and immediate discontinuation (24.9\%). Patients in the most adherent group were less likely to abuse alcohol and drugs and had fewer comorbidities as measured by the CCI. Conversely, patients in the immediate discontinuation group had the largest number of comorbidities and were more likely to abuse alcohol and drugs. Several studies have made similar connections between substance abuse and poor adherence. ${ }^{31-33}$ Consistent 
Patterns of Adherence to Oral Atypical Antipsychotics Among Patients Diagnosed with Schizophrenia

TABLE 3 Selected Membership Model Odds Ratios Relative to Adherent Group

\begin{tabular}{|c|c|c|c|c|c|}
\hline & \multicolumn{5}{|c|}{ Adherence Trajectory Group } \\
\hline & Discontinuation & Discontinuation & Discontinuation & Stop-Start & \multirow{2}{*}{$\begin{array}{c}\text { Immediate } \\
\text { Discontinuation }\end{array}$} \\
\hline & 9 Months & 6 Months & 3 Months & 6 Months & \\
\hline & $(\mathrm{n}=1,497)$ & $(n=1,937)$ & $(n=4,448)$ & $(n=4,525)$ & $(\mathrm{n}=7,361)$ \\
\hline \multicolumn{6}{|l|}{ Insurance type } \\
\hline \multirow{2}{*}{ Medicare } & 0.710 & 0.770 & $0.710^{\mathrm{a}}$ & $0.720^{\mathrm{b}}$ & $0.730^{\mathrm{b}}$ \\
\hline & $(0.139)$ & $(0.128)$ & $(0.078)$ & $(0.079)$ & $(0.064)$ \\
\hline \multirow{2}{*}{ Medicaid } & 0.860 & 0.820 & $0.570^{\mathrm{b}}$ & $0.740^{\mathrm{b}}$ & $0.500^{\mathrm{b}}$ \\
\hline & $(0.082)$ & $(0.072)$ & $(0.033)$ & $(0.044)$ & $(0.023)$ \\
\hline \multicolumn{6}{|l|}{ Commercial (reference) } \\
\hline \multicolumn{6}{|l|}{ Treatment history (6 months pre-index) } \\
\hline \multirow{2}{*}{ ED MHR admission 6 months pre-index } & 1.210 & 1.220 & $1.280^{\mathrm{b}}$ & $1.280^{\mathrm{b}}$ & $1.490^{\mathrm{b}}$ \\
\hline & $(0.103)$ & $(0.096)$ & $(0.069)$ & $(0.068)$ & $(0.064)$ \\
\hline \multirow{2}{*}{ Inpatient psych admission 6 months pre-index } & 1.130 & 1.080 & 1.100 & $0.840^{\mathrm{a}}$ & $1.150^{\mathrm{a}}$ \\
\hline & $(0.110)$ & $(0.098)$ & $(0.067)$ & $(0.053)$ & $(0.057)$ \\
\hline \multirow{2}{*}{ Share of OP visits with psychiatrist } & 0.970 & 1.160 & $0.650^{\mathrm{b}}$ & $0.840^{\mathrm{a}}$ & $0.490^{\mathrm{b}}$ \\
\hline & $(0.084)$ & $(0.088)$ & $(0.039)$ & $(0.047)$ & $(0.024)$ \\
\hline \multirow{2}{*}{ Repeat provider interactions } & $1.300^{\mathrm{b}}$ & $1.570^{\mathrm{b}}$ & $1.340^{\mathrm{b}}$ & 1.100 & $1.350^{\mathrm{b}}$ \\
\hline & $(0.098)$ & $(0.108)$ & $(0.066)$ & $(0.052)$ & $(0.053)$ \\
\hline \multicolumn{6}{|l|}{ Comorbid conditions (6 months pre-index) } \\
\hline \multirow{2}{*}{ Major depressive disorder } & 1.130 & 1.130 & $1.230^{\mathrm{b}}$ & $1.240^{\mathrm{b}}$ & 1.060 \\
\hline & $(0.078)$ & $(0.071)$ & $(0.055)$ & $(0.054)$ & $(0.038)$ \\
\hline \multirow{2}{*}{ Bipolar disorder } & 0.960 & 1.070 & 1.000 & 1.080 & $0.850^{\mathrm{b}}$ \\
\hline & $(0.065)$ & $(0.067)$ & $(0.045)$ & $(0.046)$ & $(0.031)$ \\
\hline \multirow{2}{*}{ Charlson Comorbidity Index } & 0.980 & 1.040 & $1.040^{\mathrm{a}}$ & $1.040^{\mathrm{a}}$ & $1.060^{\mathrm{b}}$ \\
\hline & $(0.027)$ & $(0.023)$ & $(0.016)$ & $(0.016)$ & $(0.014)$ \\
\hline \multirow{2}{*}{ Alcoholism } & 1.230 & 1.120 & $1.510^{\mathrm{b}}$ & $1.340^{\mathrm{b}}$ & $1.680^{\mathrm{b}}$ \\
\hline & $(0.110)$ & $(0.094)$ & $(0.085)$ & $(0.075)$ & $(0.076)$ \\
\hline \multirow{2}{*}{ Drug abuse } & $1.460^{\mathrm{b}}$ & 1.250 & $1.450^{\mathrm{b}}$ & $1.460^{\mathrm{b}}$ & $1.810^{\mathrm{b}}$ \\
\hline & $(0.1550)$ & $(0.131)$ & $(0.101)$ & $(0.101)$ & $(0.101)$ \\
\hline \multicolumn{6}{|c|}{$\begin{array}{l}\text { Note: All values are rendered as odds ratio (standard error). The odds ratio is the effect of that patient characteristic on the relative probability of membership in the } \\
\text { trajectory group compared with the adherent group and is calculated as the exponentiated logistic regression coefficient. Age category, sex, and a constant term were also } \\
\text { included in the model. Bayesian information criterion statistic }=-147,699 \text {. } \\
\text { a } P<0.01 \text {. } \\
b P<0.001 \text {. } \\
\text { ED =emergency department; MHR= mental health-related; } O P=\text { outpatient. }\end{array}$} \\
\hline
\end{tabular}

with previous studies, ${ }^{22,34}$ successively older patients had lower odds of belonging to the immediate discontinuation group than patients aged $18-24$ years.

We observed differences in the number of psychiatric inpatient admissions and MHR ED visits between the adherent group and the 5 nonadherent groups. We found that adherent patients had fewer MHR ED visits but more psychiatric inpatient admissions. We cannot rule out the possibility of reverse causality for the latter effect, since we assumed that patients are completely adherent for the duration of inpatient care. Alternatively, inpatient visits might reestablish adherence behavior so that the relationship is more than just mechanical. ${ }^{35}$ We considered examining how current adherence affects future hospitalizations, but doing so required a 30-month continuous enrollment criteria, which dramatically shrank the sample size and would likely have retained a sample of healthier individuals that was not representative of the population. On the other hand, ED use has little obvious effect on adherence behavior but might reflect illness severity. ED use is an appropriate way to assess how adherence affects the onset of acute episodes.

Although this study is the first to use GBTM to track medication adherence among patients with SMI, a number of other studies have measured adherence trends in other disease areas using GBTM. A study by Franklin et al. (2014) used a pharmacy claims database and the GBTM method to classify a large cohort of patients by their adherence to statins. ${ }^{12}$ This study had a population of more than 250,000 statin initiators and a follow-up period of 15 months. As in our study, a 6-group model best summarized statin user adherence. We found a higher proportion of patients in our adherent group than Franklin et al. did and fewer in the discontinuation groups, 
FIGURE 2 Incidence Rate Ratios for MHR ED Visits and Psychiatric Inpatient Admissions Relative to Adherent Patient Group

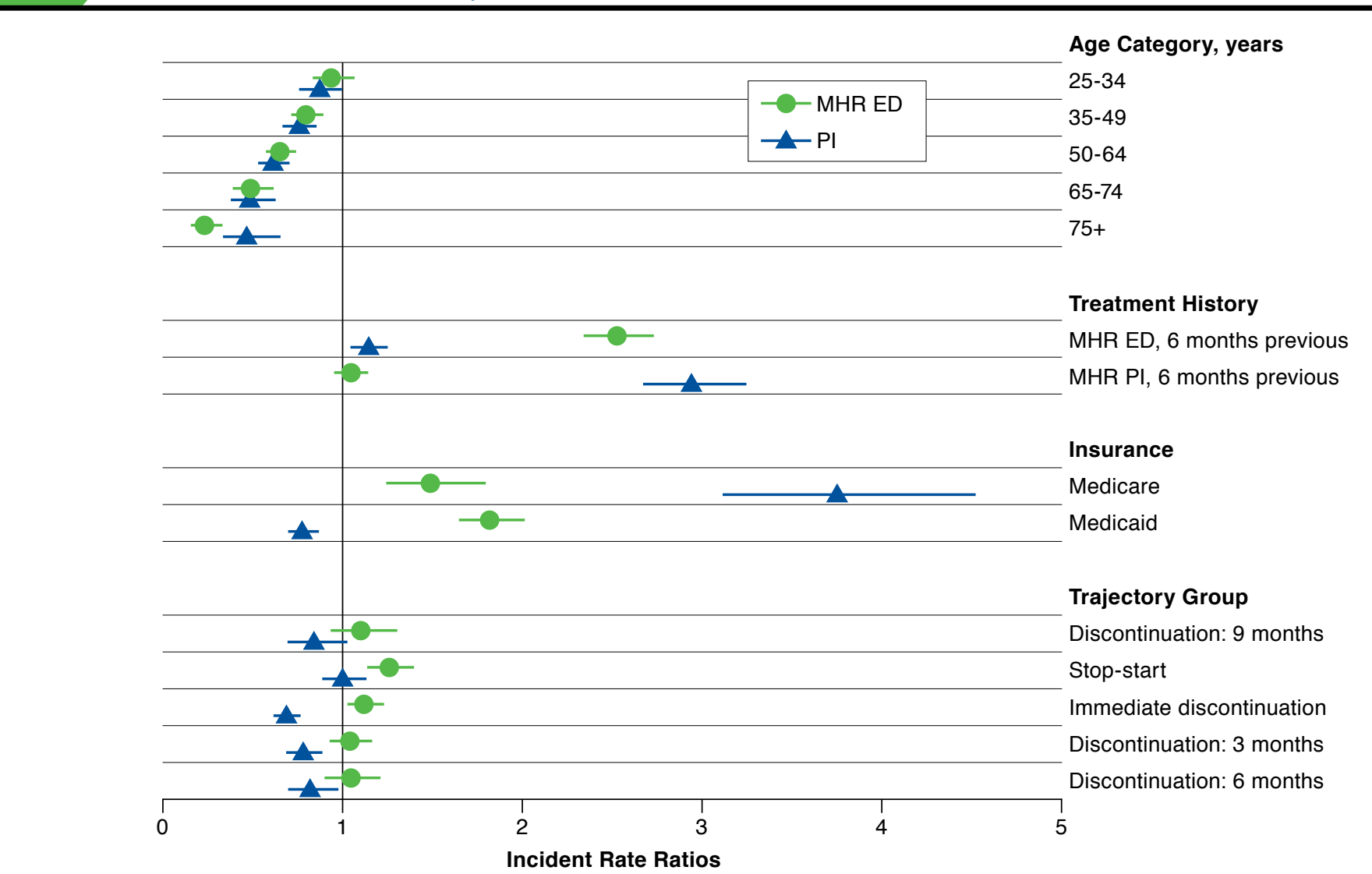

Note: $99 \%$ confidence interval bands displayed. The reference group is patients aged 18-24 years with commercial insurance in the adherent trajectory group.

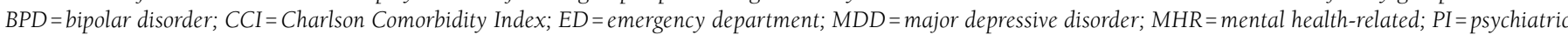
inpatient admission.

but the proportion in the immediate discontinuation groups in our study was similar to the proportion of patients identified by Franklin et al. ${ }^{12}$ This difference may stem from the longer "clean window" and higher likelihood of capturing treatment initiation-a limitation we discuss below-in Franklin et al. Previous research has shown that newly diagnosed patients may have poorer adherence to medication than established patients. ${ }^{36,37}$

Previous research has shown that timing of adherence problems has clinical and economic ramifications, and timely identification of nonadherence enables targeted intervention and prevention of further adherence deterioration. For example, using a sample of patients aged 13-65 years with commercial insurance, Offord et al. (2013) found that early adherence problems were associated with later adherence problems, more hospitalizations, longer lengths of stay, and greater health care use. ${ }^{38}$ However, claims-based studies of medication adherence among patients with schizophrenia rarely consider adherence beyond a dichotomous variable that summarizes adherence over 12 months or describes the adherence patterns of discontinuing or nonadherent subjects. In practice, the lag time associated with using claims-based measures does not facilitate timely and appropriate adherence interventions. GBTM analyses such as this one may help facilitate personalized medicine and quality assessment by helping providers target and time these interventions to nonadherent patients with schizophrenia ${ }^{12}$ by distinguishing earlier between patients who immediately discontinue and those who stop adhering at key times after the initiation of therapy. For example, for patients at higher risk of discontinuation-such as younger patients, those with a history of substance abuse, or those concurrently diagnosed with multiple serious mental illnesses-clinicians may consider regular home visits, assertive community treatment, frequent phone call reminders, or switching patients to 
a long-acting injectable antipsychotic. Patients at a lower risk could be targets for less intensive adherence intervention strategies including reminder phone calls, coordination with family members and social workers, and/or switches to simplified medication regimens.

Innovative adherence detection devices such as medication event monitoring systems (e.g., digital pillboxes and "smart" bottle caps), ingestible sensors, or other digital technologies that help patients and physicians monitor adherence much more frequently may allow for timed interventions (e.g., case management and cognitive behavioral therapy) at different points in time of nonadherence occurrence. More research is needed to determine which of these interventions can identify deterioration in adherence as early as possible.

\section{Limitations}

Patient selection for this study depends on the accuracy of diagnosis codes reported in claims data. Potential coding errors within the claims databases could lead to misidentification of schizophrenia patients and codiagnoses of schizophrenia, MDD, and/or BPD. To mitigate this risk, patients were required to have $\geq 1$ oral atypical antipsychotic prescription and $\geq 1$ inpatient or outpatient claim with a schizophrenia diagnosis, in addition to the outpatient pharmacy claim for an atypical antipsychotic. We also validated the selected ICD-9-CM diagnosis codes using previous studies. ${ }^{26,39,40}$ Additionally, the Medicaid database contains data from only 11 states. Although the commercial and Medicare databases are nationwide, they are convenience samples and do not include uninsured patients. Furthermore, the adherence calculation relied on whether the prescription was filled but not whether the drug was actually ingested. Future research could compute adherence trajectories using data gathered through real-time monitoring technologies, such as electronic pill boxes or ingestible sensors. We identify new initiation of atypical antipsychotic medications by requiring a 6-month "clean window" without any antipsychotic medication prescriptions filled before therapy initiation. This "clean window" may have enriched the sample with patients who have had problems with adherence in the past and may, therefore, have increased the proportion of patients with various nonadherent trajectories in our study. However, we cannot confirm whether patients had initiated therapy more than 6 months before initiation. The age profile of the sample suggests that our sample may be more representative of patients initiating a resumption of therapy after a period of nonuse rather than patients with early-onset psychosis.

Finally, we only consider time-invariant or fixed characteristics as predictors of trajectory membership. As many studies have shown, health care utilization is closely tied to medication adherence..$^{41}$ While poor adherence may precipitate ED visits and inpatient admissions, psychiatric inpatient visits may have an adherence-improving effect, at least during patients' stays.
A rigorous analysis of time-variant predictors of adherence trajectories would include more detailed information on patient characteristics than claims data can provide.

\section{Conclusions}

Novel approaches such as GBTM can be applied to longitudinal claims data to account for the dynamic nature of adherence. GBTM allows for the identification of distinct adherence patterns within a population and for the identification of patient characteristics for individuals within these adherence groups. Patients diagnosed with schizophrenia exhibited 6 distinct adherence patterns to oral atypical antipsychotic therapy. Adherent patients had fewer comorbidities, including fewer cooccurring SMIs, and were less likely to have a history of substance abuse. Adverse outcomes appeared to be highest among patients who were immediately nonadherent but were still substantial for those exhibiting a stop-start adherence pattern, which may escape detection if simple PDC measures are used to assess nonadherence. Health plans should consider supplementing annual claims-based adherence measures with new technologies that are able to track patient adherence patterns over time.

\section{Authors}

JOANNA P. MACEWAN, PhD, and JASON SHAFRIN, PhD, Precision Health Economics, Los Angeles, California. FELICIA M. FORMA, BSc, and AINSLIE HATCH, PhD, Otsuka Pharmaceutical Development \& Commercialization, Rockville, Maryland. DARIUS N. LAKDAWALLA, PhD, Schaeffer Center for Health Policy and Economics, University of Southern California, Los Angeles, California; and JEAN-PIERRE LINDENMAYER, MD, Department of Psychiatry, New York University, New York, New York.

AUTHOR CORRESPONDENCE: Joanna P. MacEwan, PhD, Precision Health Economics, 11100 Santa Monica Blvd., Ste. 500, Los Angeles, CA 90025. Tel.: 310.984.7718;

E-mail: Joanna.MacEwan@pheconomics.com.

\section{DISCLOSURES}

Otsuka Pharmaceutical Development \& Commercialization provided support for this research. MacEwan and Shafrin are employees of Precision Health Economics, which was contracted by Otsuka Pharmaceutical Development \& Commercialization to conduct this study. Lakdawalla is the Chief Scientific Officer and a founding partner of Precision Health Economics. Forma is an employee of Otsuka Pharmaceutical Development \& Commercialization. Hatch is a former employee of Otsuka Pharmaceutical Development \& Commercialization and is a current employee of ODH, Inc. Lindenmayer has received grant/research support from Janssen, Lilly, AstraZeneca, Johnson \& Johnson, Pfizer, BMS, Otsuka, Dainippon, and Roche and is a consultant for Janssen, Lilly, Merck, Shire, and Lundbeck.

Portions of this study were presented as a poster at the American Society of Clinical Psychopharmacology Annual Meeting in Miami Beach, Florida June 23, 2015; and at the 28th Annual U.S. Psychiatric and Mental Health Congress; San Diego, California; September 12, 2015. 
Study concept and design were contributed by Forma, Ladkawalla, MacEwan, and Shafrin, along with Hatch and Lindenmayer. MacEwan, Shafrin, Forma, and Lakdawalla collected the data, along with Hatch and Lindenmayer. Data interpretation was performed by Hatch, Lindenmayer, MacEwan, and Shafrin, assisted by Forma and Lakdawalla. The manuscript was written and revised by MacEwan, Forma, and Shafrin, along with Hatch Lakdawalla, and Lindenmayer.

\section{ACKNOWLEDGMENTS}

Megan Coombes provided medical writing assistance. Jacquelyn Chou, Alison Silverstein, and Taylor Schwartz of Precision Health Economics provided editorial and research support. C4 MedSolutions (Yardley, PA) provided editorial and design assistance funded by Otsuka Pharmaceutical Development \& Commercialization.

\section{REFERENCES}

1. Lehman AF, Lieberman JA, Dixon LB, et al. Practice Guideline for the Treatment of Patients with Schizophrenia. 2nd ed. Arlington, VA: American Psychiatric Association; 2004.

2. Lindenmayer JP, Liu-Seifert H, Kulkarni PM, et al. Medication nonadherence and treatment outcome in patients with schizophrenia or schizoaffective disorder with suboptimal prior response. J Clin Psychiatry. 2009;70(7):990-96. Available at: http://www.psychiatrist.com/jcp/article/ pages/2009/v70n07/v70n0707.aspx. Accessed September 29, 2016.

3. Hirsch S, Bowen J, Emami J, et al. A one year prospective study of the effect of life events and medication in the aetiology of schizophrenic relapse. Br J Psychiatry. 1996;168(1):49-56.

4. Ayuso-Gutierrez JL, del Rio Vega JM. Factors influencing relapse in the long-term course of schizophrenia. Schizophr Res. 1997;28(2-3):199-206.

5. Valenstein M, Copeland LA, Blow FC, et al. Pharmacy data identify poorly adherent patients with schizophrenia at increased risk for admission. Med Care. 2002;40(8):630-39.

6. Robinson D, Woerner MG, Alvir JM, et al. Predictors of relapse following response from a first episode of schizophrenia or schizoaffective disorder. Arch Gen Psychiatry. 1999;56(3):241-47. Available at: http://archpsyc.jamanetwork.com/article.aspx?articleid=204795. Accessed September 29, 2016.

7. Subotnik KL, Nuechterlein KH, Ventura J, et al. Risperidone nonadherence and return of positive symptoms in the early course of schizophrenia. Am J Psychiatry. 2011;168(3):286-92. Available at: http://ajp.psychiatryonline. org/doi/abs/10.1176/appi.ajp.2010.09010087?url_ver=Z39.88-2003\&rfr_ id $=$ ori\%3Arid\%3Acrossref.org\&rfr_dat=cr_pub\%3Dpubmed. Accessed September 29, 2016

8. Weiden PJ, Kozma C, Grogg A, Locklear J. Partial compliance and risk of rehospitalization among California Medicaid patients with schizophrenia. Psychiatr Serv. 2004;55(8):886-91. Available at: http://ps.psychiatryonline. org/doi/abs/10.1176/appi.ps.55.8.886?url_ver=Z39.88-2003\&rfr_ id=ori\%3Arid\%3Acrossref.org\&rfr_dat=cr_pub\%3Dpubmed. Accessed September 29, 2016

9. Law MR, Soumerai SB, Ross-Degnan D, Adams AS. A longitudinal study of medication nonadherence and hospitalization risk in schizophrenia. J Clin Psychiatry. 2008;69(1):47-53. Available at: http://www.psychiatrist.com/jcp/ article/Pages/2008/v69n01/v69n0107.aspx. Accessed September 29, 2016.

10. Cloutier M, Sanon Aigbogun M, Guerin A, et al. The economic burden of schizophrenia in the United States in 2013. J Clin Psychiatry. 2016;77(6):764-71. Available at: http://www.psychiatrist.com/jcp/article/pages/2016/v7 7n06/ v77n0613.aspx. Accessed September 29, 2016.

11. National Committee for Quality Assurance. Adherence to antipsychotic medications for people with schizophrenia. 2015. Available at: http://www. ncqa.org/report-cards/health-plans/state-of-health-care-quality/2015-tableof-contents/antipsychotic-medications. Accessed September 29, 2016.
12. Franklin JM, Shrank WH, Pakes J, et al. Group-based trajectory models: a new approach to classifying and predicting long-term medication adherence. Med Care. 2013;51(9):789-96.

13. Horne R, Chapman SC, Parham R, Freemantle N, Forbes A, Cooper V. Understanding patients' adherence-related beliefs about medicines prescribed for long-term conditions: a meta-analytic review of the Necessity-Concerns Framework. PLoS One. 2013;8(12):e80633. Available at: http://journals.plos.org/ plosone/article?id=10.1371/journal.pone.0080633. Accessed October 7, 2016.

14. Li Y, Zhou H, Cai B, et al. Group-based trajectory modeling to assess adherence to biologics among patients with psoriasis. Clinicoecon Outcomes Res. 2014;6:197-208. Available at: https://www.dovepress.com/group-basedtrajectory-modeling-to-assess-adherence-to-biologics-among-peer-reviewedarticle-CEOR. Accessed October 7, 2016.

15. Remington G, Teo C, Mann S, Hahn M, Foussias G, Agid O. Examining levels of antipsychotic adherence to better understand nonadherence. J Clin Psychopharmacol. 2013;33(2):261-63.

16. Barkhof E, Meijer CJ, de Sonneville LMJ, Linszen DH, de Haan L. Interventions to improve adherence to antipsychotic medication in patients with schizophrenia--a review of the past decade. Eur Psychiatry. 2012;27(1):9-18. Available at: http://www.sciencedirect.com/science/article/ pii/S0924933811000307. Accessed September 29, 2016.

17. Nagin DS. Analyzing developmental trajectories: a semiparametric, group-based approach. Psych Methods. 1999;4(2):139-57.

18. Jacobson G, Casillas G, Damico A, Neuman T, Gold M. Medicare Advantage 2016 spotlight: enrollment market update. Kaiser Family Foundation. May 11, 2016. Available at: http://kff.org/medicare/issue-brief/ medicare-advantage-2016-spotlight-enrollment-market-update/. Accessed September 29, 2016.

19. Health Insurance Portability and Accountability Act of 1996. Public Law 104-191. 1996. Available at: http://www.gpo.gov/fdsys/pkg/PLAW104publ191/html/PLAW-104publ19l.htm. Accessed September 29, 2016.

20. Patel NC, Crismon ML, Miller AL, Johnsrud MT. Drug adherence: effects of decreased visit frequency on adherence to clozapine therapy. Pharmacotherapy. 2005;25(9):1242-47. Available at: http://onlinelibrary.wiley. com/doi/10.1592/phco.2005.25.9.1242/abstract;jsessionid=9229A55EF5F9A 6F5854AA2AD08DFF7B2.f04t02. Accessed September 29, 2016.

21. CLOZARIL (clozapine) tablets, for oral use. Novartis Pharmaceuticals Revised September 2015. Available at: http://clozaril.com/wp-content/ themes/eyesite/pi/Clozaril-2015A507-10022015-Approved.pdf. Accessed September 28, 2016.

22. Valenstein M, Blow FC, Copeland LA, et al. Poor antipsychotic adherence among patients with schizophrenia: medication and patient factors. Schizophr Bull. 2004;30(2):255. Available at: http://schizophreniabulletin. oxfordjournals.org/content/30/2/255.long. Accessed September 29, 2016.

23. Sattler EL, Lee JS, Perri M, 3rd. Medication (re)fill adherence measures derived from pharmacy claims data in older Americans: a review of the literature. Drugs Aging. 2013;30(6):383-99. Available at: http://link.springer.com/ article/10.1007\%2Fs40266-013-0074-z. Accessed September 29, 2016.

24. Nau DP. Proportion of days covered (PDC) as a preferred method of measuring medication adherence. Pharmacy Quality Alliance. 2012. Available at: http://www.pqaalliance.org/images/uploads/files/PQA\%20PDC\%20vs\%20 \%20MPR.pdf. Accessed September 28, 2016.

25. Centers for Medicare \& Medicaid Services. Medicare 2016 Part C \& D Star Ratings Technical Notes. Draft. August 5, 2015. Available at: https://www. cms.gov/Medicare/Prescription-Drug-Coverage/PrescriptionDrugCovGenIn/ Downloads/2016-Technical-Notes-Preview-1-v2015_08_05.pdf. Accessed October 4, 2016.

26. Quan H, Sundararajan V, Halfon P, et al. Coding algorithms for defining comorbidities in ICD-9-CM and ICD-10 administrative data. Med Care. 2005(43)11:1130-39. 
27. Berger A, Edelsberg J, Sanders KN, Alvir JMJ, Mychaskiw MA, Oster G. Medication adherence and utilization in patients with schizophrenia or bipolar disorder receiving aripiprazole, quetiapine, or ziprasidone at hospital discharge: a retrospective cohort study. BMC Psychiatry. 2012;12(1):1. Available at: http://bmcpsychiatry.biomedcentral.com/articles/10.1186/1471244X-12-99. Accessed October 7, 2016.

28. Wu EQ, Shi L, Birnbaum H, Hudson T, Kessler R. Annual prevalence of diagnosed schizophrenia in the USA: a claims data analysis approach. Psych Med. 2006;36(11):1535-40. Available at: https://www.cambridge.org/core/ journals/psychological-medicine/article/annual-prevalence-of-diagnosedschizophrenia-in-the-usa-a-claims-data-analysis-approach/046F4BE0A6361 093DA874251EE69D562. Accessed September 29, 2016.

29. Lang K, Federico V, Muser E, Menzin J, Menzin J. Rates and predictors of antipsychotic non-adherence and hospitalization in Medicaid and commercially-insured patients with schizophrenia. J Med Econ. 2013;16(8):997-1006. Available at: https://www.ncbi.nlm.nih.gov/pmc/ articles/PMC3480886/. Accessed September 29, 2016.

30. National Institute of Mental Health. Schizophrenia. Available at: http:// www.nimh.nih.gov/health/statistics/prevalence/schizophrenia.shtml. Accessed September 29, 2016.

31. Jonsdottir H, Opjordsmoen S, Birkenaes AB, et al. Predictors of medication adherence in patients with schizophrenia and bipolar disorder. Acta Psychiatr Scand. 2013;127(1):23-33. Available at: http://onlinelibrary.wiley. com/doi/10.1111/j.1600-0447.2012.01911.x/abstract. Accessed September 29, 2016.

32. Novick D, Haro JM, Suarez D, Perez V, Dittmann RW, Haddad PM. Predictors and clinical consequences of non-adherence with antipsychotic medication in the outpatient treatment of schizophrenia. Psychiatry Res. 2010;176(2-3):109-13. Available at: http://www.sciencedirect.com/science/ article/pii/S0165178109001875. Accessed September 29, 2016.

33. Hunt GE, Bergen J, Bashir M. Medication compliance and comorbid substance abuse in schizophrenia: impact on community survival 4 years after a relapse. Schizophrenia Res. 2002;54(3):253-264. Available at: http:// www.sciencedirect.com/science/article/pii/S0920996401002614. Accessed September 29, 2016.

34. Lang K, Meyers JL, Korn JR, et al. Medication adherence and hospitalization among patients with schizophrenia treated with antipsychotics. Psychiatr Serv. 2010;61(12):1239-47. Available at: http://ps.psychiatryonline. org/doi/abs/10.1176/ps.2010.61.12.1239?url_ver=Z39.88-2003\&rfr_ id=ori\%3Arid\%3Acrossref.org $\&$ rfr_dat=cr_pub\%3Dpubmed. Accessed September 29, 2016.

35. Ascher-Svanum H, Zhu B, Faries DE, Furiak NM, Montgomery W. Medication adherence levels and differential use of mental-health services in the treatment of schizophrenia. BMC Res Notes. 2009;2(1):6. Available at: http://bmcresnotes.biomedcentral.com/articles/10.1186/1756-0500-2-6. Accessed October 7, 2016.

36. Jin J, Sklar GE, Oh VMS, Li SC. Factors affecting therapeutic compliance: a review from the patient's perspective. Ther Clin Risk Manag. 2008;4(1):269. Available at: https://www.ncbi.nlm.nih.gov/pmc/articles/PMC2503662/. Accessed September 29, 2016.

37. Caro JJ, Salas M, Speckman JL, Raggio G, Jackson JD. Persistence with treatment for hypertension in actual practice. Canadian Med Assoc J. 1999;160(1):31-37. Available at: https://www.ncbi.nlm.nih.gov/pmc/articles/ PMC1229943/. Accessed September 29, 2016.

38. Offord S, Lin J, Mirski D, Wong B. Impact of early nonadherence to oral antipsychotics on clinical and economic outcomes among patients with schizophrenia. Adv Ther. 2013;30(3):286-297. Available at: http://link.springer com/article/10.1007\%2Fs12325-013-0016-5. Accessed September 29, 2016.
39. Kannus P, Niemi S, Parkkari J, Palvanen M, Vuori I, Jarvinen M. Nationwide decline in incidence of hip fracture. J Bone Miner Res. 2006; 21(12):1836-38. Available at: http://onlinelibrary.wiley.com/doi/10.1359/ jbmr.060815/abstract. Accessed September 29, 2016.

40. Swarztrauber K, Anau J, Peters D. Identifying and distinguishing cases of parkinsonism and Parkinson's disease using ICD-9 CM codes and pharmacy data. Mov Disord. 2005;20(8):964-70. Available at: http://onlinelibrary. wiley.com/doi/10.1002/mds.20479/abstract. Accessed September 29, 2016. 41. Goldman DP, Joyce GF, Zheng Y. Prescription drug cost sharing: associations with medication and medical utilization and spending and health. JAMA. 2007;298(1):61-69. Available at: http://jama.jamanetwork.com/article. aspx?articleid=207805. Accessed September 29, 2016.

42. Karve S, Cleves MA, Helm M, Hudson TJ, West DS, Martin BC. Prospective validation of eight different adherence measures for use with administrative claims data among patients with schizophrenia. Value Health. 2009;12(6):989-95. Available at: http://www.sciencedirect.com/science/ article/pii/S1098301510602999. Accessed September 29, 2016.

43. Kamat SA, Rajagopalan K, Pethick N, Willey V, Bullano M, Hassan M. Prevalence and humanistic impact of potential misdiagnosis of bipolar disorder among patients with major depressive disorder in a commercially insured population. J Manag Care Pharm. 2008;14(7):631-42. Available at: http://www.jmcp.org/doi/abs/10.18553/jmcp.2008.14.7.632.

44. Carney CP, Jones LE. Medical comorbidity in women and men with bipolar disorders: a population-based controlled study. Psychosom Med. 2006;68(5):684-91.

45. Chabannes J, Pelissolo A, Farah S, Gerard D. [Evaluation of efficacy and tolerance of amisulpride in treatment of schizophrenic psychoses]. L'Encephale. 1997;24(4):386-92.

46. Kilbourne AM, Brar JS, Drayer RA, Xu X, Post EP. Cardiovascular disease and metabolic risk factors in male patients with schizophrenia, schizoaffective disorder, and bipolar disorder. Psychosomatics. 2007;48(5):412-17.

47. Lee TA, Pickard AS, Bartle B, Weiss KB. Osteoarthritis: a comorbid marker for longer life? Ann Epidemiol. 2007;17(5):380-84. Available at: http:// www.sciencedirect.com/science/article/pii/S1047279707000518. Accessed September 29, 2016.

48. Iribarren C, Sidney S, Sternfeld B, Browner WS. Calcification of the aortic arch: risk factors and association with coronary heart disease, stroke, and peripheral vascular disease. JAMA. 2000;283(21):2810-15. Available at: http://jama.jamanetwork.com/article. aspx?articleid=192762. Accessed September 29, 2016.

49. Stempel D, Stoloff S, Carranza Rosenzweig J, Stanford R, Ryskina K, Legorreta A. Adherence to asthma controller medication regimens. Respir Med. 2005;99(10):1263-67. Available at: http://www.sciencedirect.com/science/article/pii/S095461110500096X. Accessed September 29, 2016.

50. O'Donohue WJ. Guidelines for the use of nebulizers in the home and at domiciliary sites. Report of a consensus conference. CHEST Journal. 1996;109(3):814-20. Available at: http://www.sciencedirect.com/science/ article/pii/S0012369215458738. Accessed September 29, 2016.

51. Mullins CD, Cooke Jr JL, Wang J, Shaya FT, Van Hsu D, Brooks S. Disparities in prevalence rates for lung, colorectal, breast, and prostate cancers in Medicaid. J Natl Med Assoc. 2004;96(6):809. Available at: https://www. ncbi.nlm.nih.gov/pmc/articles/PMC2568358/. Accessed September 29, 2016.

52. Weycker D, Macarios D, Edelsberg J, Oster G. Compliance with drug therapy for postmenopausal osteoporosis. Osteoporosis Int. 2006;17(11):1645-52. Available at: http://link.springer.com/article/10.1007\%2Fs00198-0060179-x. Accessed September 29, 2016. 
APPENDIX A Patient Characteristics by Adherence Trajectory Group

\begin{tabular}{|c|c|c|c|c|c|c|c|}
\hline & \multicolumn{6}{|c|}{ Adherence Trajectory Group } & \multirow[b]{3}{*}{ Overall } \\
\hline & \multirow[b]{2}{*}{ Adherent } & Discontinuation & Discontinuation & Discontinuation & Stop-Start & \multirow{2}{*}{$\begin{array}{c}\text { Immediate } \\
\text { Discontinuation }\end{array}$} & \\
\hline & & 9 Months & 6 Months & 3 Months & 6 Months & & \\
\hline & $(n=9,838)$ & $(n=1,497)$ & $(n=1,937)$ & $(n=4,448)$ & $(n=4,525)$ & $(\mathbf{n}=7,361)$ & $(\mathrm{N}=29,607)$ \\
\hline Percentage of total sample & 33.2 & 5.1 & 6.5 & 15.0 & 15.3 & 24.9 & 100.0 \\
\hline \multicolumn{8}{|l|}{ Age category, \% (SD) } \\
\hline $18-24$ years & $8.4 \quad(27.8)$ & $10.7(30.9)$ & $8.9(28.5)$ & $13.7(34.4)$ & $11.7(32.1)$ & $13.4(34.1)$ & $11.1 \quad(31.4)$ \\
\hline $25-34$ years & $15.3(36.0)$ & $17.0(37.5)$ & $14.6(35.3)$ & $19.2(39.4)$ & $17.0(37.6)$ & $20.1(40.1)$ & $17.4(37.9)$ \\
\hline $35-54$ years & $34.8(47.6)$ & $38.6(48.7)$ & $34.8(47.7)$ & $35.1 \quad(47.7)$ & $37.1(48.3)$ & $34.7(47.6)$ & $35.3(47.8)$ \\
\hline $54-64$ years & $34.0 \quad(47.4)$ & $27.0(44.4)$ & $34.1 \quad(47.4)$ & $26.0(43.9)$ & $28.0(44.9)$ & $27.8(44.8)$ & $30.0(45.8)$ \\
\hline $65-74$ years & $5.0(21.9)$ & $4.9(21.6)$ & $4.6(20.9)$ & $4.3(20.4)$ & $4.3(20.2)$ & $2.9(16.9)$ & $4.2(20.2)$ \\
\hline $75+$ years & $2.4(15.3)$ & $1.8(13.4)$ & $3.0(17.1)$ & $1.7(12.9)$ & $1.9(13.5)$ & $1.1(10.5)$ & $1.9(13.7)$ \\
\hline Female, \% (SD) & $50.9(50.0)$ & $50.2(50.0)$ & $49.9(50.0)$ & $51.3(50.0)$ & $51.8(50.0)$ & $51.9(50.0)$ & $51.3(50.0)$ \\
\hline \multicolumn{8}{|l|}{ Insurance type, \% (SD) } \\
\hline Medicare & $5.3(22.4)$ & $3.8(19.2)$ & $4.6(21.0)$ & $5.6(23.1)$ & $4.9(21.5)$ & $5.9(23.5)$ & $5.3(22.4)$ \\
\hline Medicaid & $80.4(39.7)$ & $80.0(40.0)$ & $78.3(41.2)$ & $72.0(44.9)$ & $76.9(42.1)$ & $70.7(45.5)$ & $76.0(42.7)$ \\
\hline Commercial & $14.3(35.0)$ & $16.2(36.9)$ & $17.1(37.6)$ & $22.4(41.7)$ & $18.2(38.6)$ & $23.4(42.3)$ & $18.6(38.9)$ \\
\hline \multicolumn{8}{|c|}{ Treatment history (6 months pre-index), \% (SD) } \\
\hline $\begin{array}{l}\text { ED MHR admission } \\
6 \text {-month pre-index }\end{array}$ & $15.4(36.1)$ & $20.2(40.1)$ & $20.0(40.0)$ & $25.0(43.3)$ & $22.9(42.0)$ & $27.8(44.8)$ & $21.7(41.2)$ \\
\hline $\begin{array}{l}\text { Inpatient psych admission } \\
6 \text { month pre-index }\end{array}$ & $13.1(33.7)$ & $17.8(38.3)$ & $16.6(37.3)$ & $22.8(42.0)$ & $16.7(37.3)$ & $24.6(43.1)$ & $18.4(38.8)$ \\
\hline $\begin{array}{l}\text { Share of OP visits with } \\
\text { psychiatrist }\end{array}$ & $24.7(41.8)$ & $26.2(42.5)$ & $32.3(45.1)$ & $20.1(37.9)$ & $22.6(40.0)$ & $16.8(35.0)$ & $22.3(39.8)$ \\
\hline Repeated provider interactions & $36.4(48.1)$ & $41.8(49.3)$ & $48.4(50.0)$ & $38.1(48.6)$ & $37.0(48.3)$ & $36.3(48.1)$ & $37.8(48.5)$ \\
\hline \multicolumn{8}{|c|}{ Codiagnoses and other conditions (6 months pre-index), \% (SD) } \\
\hline MDD & $45.6(49.8)$ & $51.6(50.0)$ & $51.4(50.0)$ & $57.1(49.5)$ & $55.5(49.7)$ & $55.2(49.7)$ & $51.9(50.0)$ \\
\hline BPD & $40.1(49.0)$ & $43.0(49.5)$ & $44.3(49.7)$ & $47.7(50.0)$ & $47.2(49.9)$ & $45.3(49.8)$ & $44.0(49.6)$ \\
\hline $\mathrm{CCI}$ & $0.6 \quad(1.4)$ & $0.6 \quad(1.3)$ & $0.8 \quad(1.4)$ & $0.8 \quad(1.4)$ & $0.7 \quad(1.4)$ & $0.8 \quad(1.5)$ & $0.7 \quad(1.4)$ \\
\hline Alcoholism & $15.3(36.0)$ & $21.3(41.0)$ & $19.6(39.7)$ & $26.7(44.2)$ & $23.4(42.3)$ & $29.6(45.7)$ & $22.4(41.7)$ \\
\hline Drug abuse & $7.8(26.9)$ & $12.9(33.6)$ & $11.3(31.6)$ & $15.5(36.2)$ & $13.5(34.2)$ & $18.5(38.9)$ & $13.0(33.7)$ \\
\hline \multicolumn{8}{|c|}{ Adherence (12 months post-index), \% (SD) } \\
\hline $\mathrm{PDC}$ & $98.9 \quad(3.2)$ & $76.4(11.1)$ & $69.7(14.4)$ & $42.6(13.1)$ & $74.3(17.1)$ & $18.4(12.2)$ & $63.4(34.2)$ \\
\hline \multicolumn{8}{|l|}{ PDC categorical } \\
\hline $0 \%-25 \%$ & $(0.0)$ & $0.0 \quad(0.0)$ & $0.0 \quad(0.0)$ & $1.6(12.5)$ & $0.0 \quad(0.0)$ & $71.3(45.2)$ & $18.8(39.1)$ \\
\hline $26 \%-50 \%$ & $(1.0)$ & $1.0 \quad(9.7)$ & $1.6(12.5)$ & $66.7(47.1)$ & $7.8(26.8)$ & $25.5(43.6)$ & $17.2(37.7)$ \\
\hline $51 \%-75 \%$ & $(1.0)$ & $30.7(46.1)$ & $62.0(48.6)$ & $29.3(45.5)$ & $35.3(47.8)$ & $3.0(17.1)$ & $15.8(36.5)$ \\
\hline $76 \%-100 \%$ & $100.0 \quad(1.4)$ & $68.4(46.5)$ & $36.4(48.1)$ & $2.4(15.4)$ & $56.9(49.5)$ & $0.2 \quad(3.9)$ & $48.2(50.0)$ \\
\hline \multicolumn{8}{|c|}{ Acute care use (12 months post-index), \% (SD) } \\
\hline ED visits, $\mathrm{n}$ & $1.7 \quad(4.1)$ & $2.1 \quad(4.5)$ & $(4.3)$ & $(4.8)$ & $(5.1)$ & $(6.8)$ & $(5.2)$ \\
\hline Inpatient admissions, $\mathrm{n}$ & $(5.6)$ & $0.6 \quad(2.2)$ & $(2.1)$ & $(1.8)$ & $(3.4)$ & $(1.4)$ & (3.7) \\
\hline
\end{tabular}

Note: The full distribution of the categorical variables is reported.

$B P D=$ bipolar disorder; $C C I=$ Charlson Comorbidity Index; $E D=$ emergency department; $M D D=$ major depressive disorder; $M H R=$ mental health-related; $O P=$ outpatient; $P D C=$ proportion of days covered; $S D=$ standard deviation . 
APPENDIX B Bayesian Information Criteria Comparison Across Number of Groups

\begin{tabular}{|c|c|c|c|c|c|c|c|c|}
\hline \multirow[b]{2}{*}{ Model Number } & \multirow{2}{*}{$\begin{array}{l}\text { Number of } \\
\text { Groups }\end{array}$} & \multirow[b]{2}{*}{ BIC } & \multicolumn{6}{|c|}{ Percentage of Patients in Each Group } \\
\hline & & & 1 & 2 & 3 & 4 & 5 & 6 \\
\hline- & 2 & $-166,784$ & 51.1 & 48.9 & - & - & - & - \\
\hline $\mathrm{A}$ & 3 & $-156,159$ & 32.2 & 31.5 & 36.4 & - & - & - \\
\hline $\mathrm{B}$ & 4 & $-150,489$ & 15.0 & 32.7 & 17.5 & 34.9 & - & - \\
\hline $\mathrm{C}$ & 5 & $-148,503$ & 14.0 & 27.1 & 16.2 & 10.1 & 32.7 & - \\
\hline $\mathrm{D}$ & 6 & $-147,699$ & 5.1 & 15.3 & 24.9 & 15.0 & 33.2 & 6.5 \\
\hline
\end{tabular}

